\title{
Lowering the level of occupational exposure to noise in areas neighbouring compressor halls
}

\author{
Sorin Simion*, Alexandru Simion, Izabella Kovacs, and Vlad Lautaru \\ National Institute for Research and Development in Mine Safety and Protection to Explosion - \\ INSEMEX Petroşani, 32-34 G-ral Vasile Milea Street, Postcode: 332047, Petroşani, Hunedoara \\ County, Romania
}

\begin{abstract}
A general problem in the vicinity of industrial compressors is the noise generated in the working environment by their operation. A large number of workers suffer from hearing problems caused by exposure to high levels of noise in the workplace. Thus, legal provisions regulating occupational noise exposure aim to reduce the risk of hearing loss by reducing noise level, the most effective measures being those applied directly to the noise source combined with the use of hearing protection. Quantification of noise exposure level and mitigation of occupational hazards generated by it at each workplace is required in order to prevent accidents and occupational diseases. The current paper analyses how noise generated by industrial compressors influences worker's activity. Prevention of noise exposure must be based on noise level measurements. In this sense, the purpose of the paper is to analyse noise measurements performed at a compressor hall and to compare the values obtained with limit values set by in force legislation, in order to apply the best technical organizational methods for lowering noise exposure and increasing acoustic comfort in order to improve working conditions of those working in the compressor hall.
\end{abstract}

\section{Introduction}

One of the main institutions of Labour law is safety and health at work, which has been given special attention both in the conventions of international organizations with concerns in the field as well as in national legislation.

The fundamental purpose of occupational safety and health is protection of life, body integrity and health of employees and other persons involved in the work process. The need to establish unitary, coherent and efficient norms in this field gathers way even more in a transitional economy where, because of all kinds of constraints, there can be encountered situations in which granting material and financial resources needed for ensuring minimum standards is neglected. [1] Three components of the occupational safety and health notion are identified: scientific discipline, legal institution and methodological-practical activity. The

* Corresponding author: sorin.simion@insemex.ro 
legislative system of occupational safety and health is complex and includes a complex system of legislative acts harmonized with the Community standards. The framework law is "Law 319/2006 [2] - on occupational safety and health" which transposed Directive 89/391/EEC. [3]

Enacting of principles included in the Framework Directive 89/391/EEC is really indispensable in establishing a system of protection of health and safety at work in line with the one in the European Union and the Directive 2003/10/EC adopted by GD 493/2006 regarding the minimum security requirements regarding the exposure of workers to risks generated by noise. [4]

The objective of the current paper is generic introduction to the plan of specific measures to reduce noise level at workplaces in compressor areas. In order to identify the places susceptible of occupational exposure to noise noxae, noise levels were measured respectively spectrograms of work places where a complex of noise mitigation measures should be applied were established.

\section{Working tools}

Noise level was measured with the use of Bruel \& Kjaer type 2250 integrating sound meters equipped with one-octave and/ or $1 / 3$ octave filters, Bruel \& Kjaer type 4231 calibrators and BZ 5503 measurements visualization software.

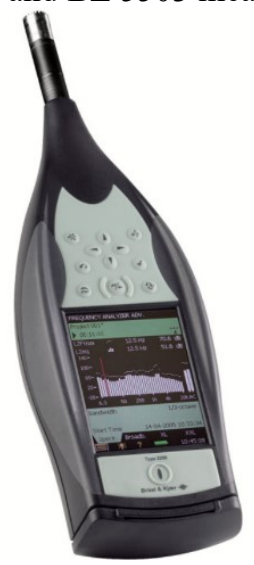

Fig.1. 2250 type Analyser

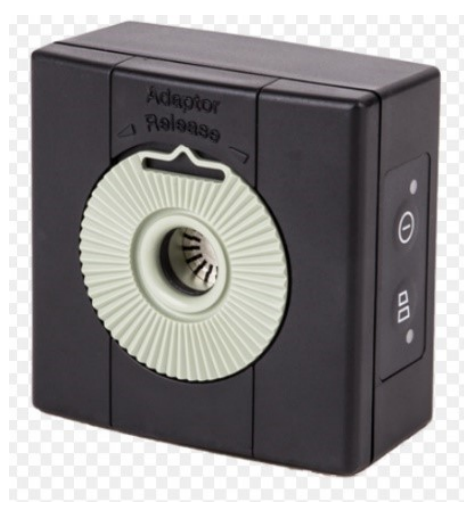

Fig.2. 4231 type Acoustic calibrator

The 2250 type noise analyser (fig.1.) is used to perform individual measurement series or measurement series for laboratory and in situ analysis. The acoustic calibrator (fig.2.) is used when checking sound meters to obtain results with a high degree of accuracy (the check is performed both before and after a series of measurements). In order to ensure the quality of results the sound meters and calibrators used were verified according to requirements set by in force legislation. [3]

If the calibration differs by more than $\pm 1.5 \mathrm{~dB}$ from the initial one, then the sound meter used is checked to see if it corresponds metrologically.

\section{Case study}

In order to meet the requirements necessary for implementing noise reduction measures, noise level measurements were made in the compressor hall taking into account the location of main noise generating equipment. The spectral analysis performed is necessary to obtain 
data regarding the characteristics of noise generated by equipment for choosing the soundabsorbing / sound-insulating materials compatible with the particularities of analysed noise. Evaluation of the efficiency of different technical versions suggested or foreseen in order to reduce noise level for workers at the reception points considered as sensitive, must be performed taking into account noise characteristics (noise level according to frequency) [5].

The results of spectral analyses for the measurement points in the Compressor Hall and noise level values for each measurement point are presented below (table 1).

Data thus obtained are used for establishing the optimal technical solutions for reducing noise level at points of interest in order to increase the degree of safety and health at work.

The location of the measuring points was made so that all main sources of noise within the compressor hall were covered. [6]

Measurements were taken in normal operating mode, at maximum capacity, after the scheduled revisions of compressors.

Table 1. Results of noise spectral analysis

\begin{tabular}{|c|c|c|c|c|c|c|c|c|c|c|c|c|c|c|}
\hline \multirow{2}{*}{ No. } & \multirow{2}{*}{$\begin{array}{c}\text { Noise } \\
\text { level } \\
\text { dB(A) }\end{array}$} & \multirow{2}{*}{$\begin{array}{c}\text { Noise } \\
\text { curves }\end{array}$} & \multicolumn{12}{|c|}{ Frecquency } \\
\hline & & & $5 \mathrm{~Hz}$ & 31.5 & $63 \mathrm{~Hz}$ & $125 \mathrm{~Hz}$ & $250 \mathrm{U}$ & $0 \mathrm{~Hz}$ & $1 \mathrm{kHz}$ & $\mathrm{kF}$ & $\overline{\mathrm{kl}}$ & $\mathrm{kH}$ & $16 \mathrm{kHz}$ & $20 \mathrm{kHz}$ \\
\hline 1 & 85.0 & 81 & 80.11 & 68.13 & \begin{tabular}{|l|}
67.9 \\
\end{tabular} & 74.84 & 73.4 & 78.16 & 75.67 & 73.1 & 70.14 & 44.42 & 56.41 & 52.23 \\
\hline 2 & 84.9 & 30 & 79.04 & 68.95 & 68.12 & 75.51 & 75.7 & 77.09 & 74.2 & 72.46 & 70.55 & 5.19 & 7.49 & 291 \\
\hline 3 & 85.2 & 80 & 74.65 & 70.07 & \begin{tabular}{|l|l|}
68.87 \\
\end{tabular} & 76.11 & 77.13 & 78.75 & 74.57 & 72.63 & 70.61 & 55.32 & 57.58 & 53.33 \\
\hline 4 & 85.2 & 81 & 72.58 & 68.84 & \begin{tabular}{|l|l|}
68.4 \\
\end{tabular} & 76.61 & 73.93 & 77.23 & 74.74 & 73.21 & 70.79 & 5.85 & 58.3 & 53.56 \\
\hline 5 & 87.7 & $5<$ & 74.86 & 70.08 & 69.58 & 82.97 & 75.2 & 78.1 & 77.03 & 76.37 & 74.34 & 1.21 & 67.26 & 06 \\
\hline 6 & 90.0 & 0 & 73.97 & 69.61 & 69.86 & 78.23 & 75.5 & 79.8 & 79.34 & 79.0 & 78.5 & 75.1 & 71.64 & 42 \\
\hline 7 & 87.6 & 83 & \begin{tabular}{|l|l|}
72.67 \\
\end{tabular} & 70 & 69.46 & 78.95 & 76.14 & 77.96 & 78.89 & 74.77 & 73.18 & 70.15 & 66 & \begin{tabular}{|l|l|}
62.87 \\
\end{tabular} \\
\hline 8 & 87.6 & & 74.98 & 69.93 & 68.32 & 76.06 & 78.8 & 80.5 & 76.76 & 75.56 & 73.32 & 73.07 & 70.84 & \begin{tabular}{|l|l|}
69.17 \\
\end{tabular} \\
\hline 9 & 87.9 & 8 & 73.42 & 69.93 & 70.87 & 79.62 & 80.55 & 79.58 & 77.51 & 76.15 & 74.42 & 9.36 & 64.36 & 60.56 \\
\hline 10 & 90.0 & $8 c$ & \begin{tabular}{|l|}
74.07 \\
\end{tabular} & 68.85 & 70.83 & \begin{tabular}{|l|}
83.19 \\
\end{tabular} & 83.53 & 80.58 & 79.4 & 79.78 & 78.11 & 71.5 & 65.71 & 62.06 \\
\hline 11 & 88.0 & & 74.39 & 70.27 & 69.04 & \begin{tabular}{|l|l|}
76.94 \\
\end{tabular} & 77.85 & 80.14 & 76.98 & 76.83 & 74.15 & 99.54 & 66.8 & 65.65 \\
\hline 12 & 87.9 & & 73.53 & 71 & \begin{tabular}{|l|}
70.5 \\
\end{tabular} & 80.98 & 76.57 & 79.13 & 77.01 & 75.32 & 77.65 & 99.75 & 65.63 & 62.93 \\
\hline 13 & 88.3 & & 73.44 & 69.86 & 70.76 & 86.04 & 76.53 & 76.35 & 76.76 & 75.12 & 79.44 & 8.44 & 3.99 & 59.63 \\
\hline 14 & 89.1 & 87 & \begin{tabular}{|l|l}
73.87 \\
\end{tabular} & 69.02 & 71.81 & 85.64 & 78.88 & 78.73 & 78.83 & 76.34 & 79.5 & 69.13 & 62.15 & \begin{tabular}{|l|l|}
58.47 \\
\end{tabular} \\
\hline 15 & 89.0 & 86 & 75.18 & 68.97 & 70.78 & \begin{tabular}{|l|l|}
77.14 \\
\end{tabular} & 76.26 & 78.12 & 80.32 & 75.09 & 78.7 & 77.08 & 5959 & \begin{tabular}{|l|l|}
55.27 \\
\end{tabular} \\
\hline 16 & 88.1 & & & & 72.34 & & & & 77.23 & 74.68 & 79.02 & 7.62 & & \\
\hline 17 & 89.7 & & 4.68 & 70 & 70.23 & \begin{tabular}{|l|l|}
88.93 \\
\end{tabular} & 75.25 & \begin{tabular}{|l}
78.87 \\
\end{tabular} & 77.78 & 75.18 & 81.53 & 69.87 & 16 & \begin{tabular}{|l|l|}
64.04 \\
\end{tabular} \\
\hline 18 & 91.2 & 89 & 75.28 & 69.24 & 71.15 & 85.65 & 78.61 & 81.14 & 78.12 & 75.6 & 83.02 & 68.46 & 57.48 & 54.42 \\
\hline 19 & 90.5 & 90 & \begin{tabular}{|l|l|}
75.27 \\
\end{tabular} & 69.79 & 71.53 & \begin{tabular}{|l|l|}
80.56 \\
\end{tabular} & 76.82 & 76.69 & 78.29 & 75.78 & 86.26 & 68.58 & 57.63 & \begin{tabular}{|l|l|}
54.49 \\
\end{tabular} \\
\hline 20 & 95.3 & & 81 & & 75.99 & 74. & 73.02 & 77.45 & 78.08 & 79.68 & 90.1 & 15 & 69.46 & 63.44 \\
\hline 21 & 92.9 & 9 & \begin{tabular}{|l|}
76.58 \\
\end{tabular} & 70 & \begin{tabular}{|l|}
74.06 \\
\end{tabular} & \begin{tabular}{|l|}
77.44 \\
\end{tabular} & 75.31 & 77 & 77.99 & 77.25 & 87.72 & 71.32 & 57.01 & \begin{tabular}{|l|}
50.37 \\
\end{tabular} \\
\hline 22 & 96 & 97 & \begin{tabular}{|l|l|}
79.68 \\
\end{tabular} & 73.96 & 77.26 & \begin{tabular}{|l|l|}
77.16 \\
\end{tabular} & 74.13 & 81.31 & 78.83 & 80.49 & 90.79 & 73.56 & 61.3 & 54.22 \\
\hline 23 & 92.2 & 91 & \begin{tabular}{|l|l|}
81.27 \\
\end{tabular} & 70.13 & 71.48 & \begin{tabular}{|l|l|}
82.72 \\
\end{tabular} & 80.24 & 82.09 & 80.7 & 80.11 & 82.51 & 78.88 & 72.78 & \begin{tabular}{|l|l|}
69.62 \\
\end{tabular} \\
\hline 24 & 92.2 & 9 & \begin{tabular}{|l|}
77.9 \\
\end{tabular} & 68.25 & \begin{tabular}{|l|}
71.5 \\
\end{tabular} & 82.86 & \begin{tabular}{|l|}
82.09 \\
\end{tabular} & \begin{tabular}{|l|l}
81.73 \\
\end{tabular} & 82.28 & 79.78 & 82.32 & 76.3 & 67.27 & \begin{tabular}{|l|}
62.67 \\
\end{tabular} \\
\hline
\end{tabular}

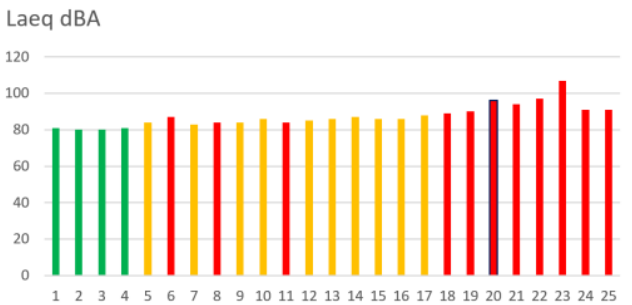

$\mathrm{Cz}$

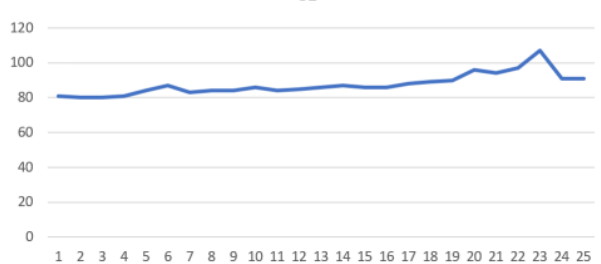

Fig. 3. Noise level charts in the compressor hall

Noise reduction is a system problem, in which the combination takes place between the source of noise-environment (propagation path) and the receiver. 
Measures designed to achieve noise reduction can be applied directly to both the source producing it and to the receiver or the path from source to receiver. In the technique of noise reduction, we distinguish on the one hand active protection which aims to eliminate those sound sources that, by a faulty conception, produce noise or vibrations of excessive intensities, and on the other hand passive protection which aims to increase the resistance which the transmission environment can oppose to acoustic waves. [7]

Noise reduction solutions for compressors described by literature are not applicable for the present case, because corrosive chemicals (caustic soda, ammonia, etc.) are present in the workplaces. Also, the operation of compressors generates a relatively high temperature $\left(32^{\circ} \mathrm{C}\right)$ in the working environment, impeding the use of classic casing solutions. The compressors used in the chemical industry are located relatively close to the technological flow, with no possibility of removing the human factor involved in monitoring and control of the technological process. It follows that, in the given situation, the use of sound-absorbing panels represents the optimal solution of reducing occupational exposure to noise of workers in immediate vicinity of compressors.

\subsection{Noise damping calculation by fitting sound absorbing screens}

Fitting sound-absorbing screens in the compressor hall in order to avoid the emission upon workstations in the immediate vicinity must take into account the fact that the efficiency of the sound-absorbing screens is different depending on sound frequency. [8][9]

The efficiency of sound-absorbing screens according to sound frequency of the is calculated with the relation:

For frequencies up to $500 \mathrm{~Hz}$

$$
\Delta L=-20 \lg \frac{l 1_{1} \cdot l_{2}}{h_{h} \cdot h_{2}}
$$

For frequencies between $500 \mathrm{~Hz}$ and $1000 \mathrm{~Hz}$

$$
\Delta L=-20 \lg \frac{l l_{1} \cdot l_{2}}{h_{h} \cdot h_{2}}+2.5\left(\frac{f}{500}-1\right)
$$

For frequencies higher than $1000 \mathrm{~Hz}$ :

Where

$$
\Delta L=-20 \lg \frac{l 1_{1} \cdot l_{2}}{h_{h} \cdot h_{2}}+3.5\left(\frac{f}{1000}-1\right)-6
$$

$1_{1}$ distance from source to screen

$1_{2}$ distance from screen to worker

$$
\begin{aligned}
& h_{1}=\sqrt{1_{1}^{2}+r_{0}^{2}}=\sqrt{14.049}=3.74 \\
& h_{2}=\sqrt{1_{2}^{2}+r_{0}^{2}}=4.306 \\
& r_{0}=\sqrt{\frac{s_{0}}{\pi}}=3.09
\end{aligned}
$$

$\mathrm{S}_{\mathrm{e}}$ screen surface $=30 \mathrm{~m}^{2}$

$\mathrm{r}$ - the radius of the circle whose surface is equivalent to that of the screen itself $\mathrm{f}-$ frequencies

As a result of calculations, the following reduction values on frequency resulted (table 2):

Table 2. Reduction values

\begin{tabular}{|c|c|c|c|c|c|c|}
\hline $\mathrm{f}(\mathrm{Hz})$ & 250 & 500 & 1000 & 2000 & 4000 & 8000 \\
\hline$\Delta \mathrm{L}$ & 11.09 & 11.09 & 13.59 & 8.59 & 15.59 & 29.59 \\
\hline
\end{tabular}




\section{Conclusions}

The results obtained after measuring the noise levels in the compressor hall show exceedances of maximum allowed limit of $87 \mathrm{~dB}$ (A) with values up to $9 \mathrm{~dB}$ (A). Thus, the spectrograms (showed above) were drawn up to establish the characteristics of noise produced at workplaces with noise level above $87 \mathrm{~dB}(\mathrm{~A})$.

Analysis of spectrograms showed that exceedances are in the bands of medium and high frequencies, considered dangerous, with values between $0.1-9 \mathrm{~dB}$, being necessary to take technical and organizational measures.

Fitting sound-absorbing screens in the compressor room to avoid emission upon workplaces in the immediate vicinity took into account that the efficiency of sound-absorbing screens differs depending on sound frequency.

Implementing soundproofing solutions by using soundproofing panels at workplaces with noise levels above $87 \mathrm{~dB}(\mathrm{~A})$ is much more economically efficient for normalizing working conditions, as opposed to endowment with quiet equipment or changing working technology.

\section{References}

1. Draghici, Angelica; Kovacs, Marius; Toth, Lorand : Occupational Health And Safety Regarding The Exposure To Noxious Of Workers From The Steel Industry by: Metalurgia international Volume: 18 Special Issue: 2 Pages: 147-153 (2013)

2. Vasilescu, Gabriel Dragos; Draghici, Angelica Nicoleta; Baciu, Constantin: Methods For Analisys And Evaluation Of Occupational Accidents And Diseases Risks, Environmental engineering and management journal Volume: 7 Issue: 4 Pages: 443-446 (2008)

3. Sorin, Simion; Ciprian, Vreme; Marius, Kovacs: Exposure of workers to noise in mining industry, Edited by: Herisanu, N; Marinca, V, Conference: 12th International Symposium Acoustics and Vibration of Mechanical Structures (AVMS 2013) Location: Timisoara, (2013)

4. Simion Spiridon, Simion Sorin: Prevention and reduction of noise emissions from industrial mining processes, INSEMEX Publishing House, Petroșani, ISBN: 978-973-88753-0-2 (2008)

5. $* * *$ Directive 2002/49/EC of the European Parliament and of the Council of 25 June 2002 relating to the assessment and management of environmental noise.

6. *** Law 319/2006 Law on Safety and Health at Work

7. Hericon Homepage, http://hericon.ro/panouri_sandwich/panou_fonoizolante.html, last accessed 2019/02/02.

8. Marcegaglia Homepage, http://www.marcegaglia.ro/marcegaglia_product/parapeteantifonice-de-siguranta-integrate-panouri-fonoabsorbante-100-al-pe/, last accessed 2019/02/02

9. ACOUSTIC DESIGN Homepage, https://sites.google.com/site/controlzgomot/solutiiacustice/panouri-acustice, last accessed 2019/02/02 